See Article page 1546.

\title{
Commentary: Stay calm amid the agonal storm in controlled lung donation after circulatory determination of death
}

\author{
Dirk Van Raemdonck, MD, PhD, a,b \\ Laurens J. Ceulemans, MD, PhD, \\ Ina Jochmans, $\mathrm{MD}, \mathrm{PhD},{ }^{\mathrm{c}, \mathrm{d}}$ and \\ Arne Neyrinck, MD, $\mathrm{PhD}^{\mathrm{e}, \mathrm{f}}$
}

Breathe deeply and step back is common advice to keep calm in stressful circumstances. This might be especially true in controlled lung donors after circulatory determination of death (cDCDDs) where warm ischemic time (WIT) dictates outcome. The variable period of progressive hypoxia and hypotension between withdrawal of lifesustaining therapy (WLST), asystole and death determination may result in abandoning organ procurement when prolonged cardiopulmonary instability occurs because the risk of serious graft injury jeopardizing recipient outcome. ${ }^{1}$ Different time intervals from WLST to asystole (agonal phase) and to flush-cooling of lungs (asystolic phase) were defined by the International Society for Heart and Lung Transplantation ${ }^{2}$ and the European Society for Organ Transplantation $^{3}$ (Table 1).

Compared with other solid organs, cDCDD lungs tolerate WIT well. In a multivariable analysis of International Society for Heart and Lung Transplantation DCD Registry data, no association of agonal time (T0-T3) and functional WIT (T2-T5) on 1-year recipient mortality after lung transplantation (LTx) was found. ${ }^{4}$ In their report, Qaqish and colleagues ${ }^{5}$ from the University of Toronto demonstrate that lungs with an agonal phase $>60$ minutes can be safely

\footnotetext{
From the Departments of ${ }^{\mathrm{a}}$ Thoracic Surgery, ${ }^{\mathrm{c}}$ Abdominal Transplant Surgery, and ${ }^{\mathrm{e}}$ Anesthesiology, University Hospitals Leuven, Leuven, Belgium; and Departments of ${ }^{\mathrm{b}}$ Chronic Diseases and Metabolism, ${ }^{\mathrm{d}}$ Microbiology, Immunology, and Transplantation, ${ }^{\mathrm{f}}$ Cardiovascular Sciences, Katholieke Universiteit Leuven, Leuven, Belgium.

Disclosures: The authors reported no conflicts of interest.

The Journal policy requires editors and reviewers to disclose conflicts of interest and to decline handling or reviewing manuscripts for which they may have a conflict of interest. The editors and reviewers of this article have no conflicts of interest.

Received for publication May 15, 2020; accepted for publication May 20, 2020; available ahead of print June 6, 2020

Address for reprints: Dirk Van Raemdonck, MD, PhD, Department of Thoracic Surgery, University Hospital Gasthuisberg, Herestraat 49, B-3000 Leuven, Belgium (E-mail: dirk.vanraemdonck@uzleuven.be).

J Thorac Cardiovasc Surg 2021;161:1556-8

$0022-5223 / \$ 36.00$

Copyright (c) 2020 by The American Association for Thoracic Surgery

https://doi.org/10.1016/j.jtcvs.2020.05.080
}

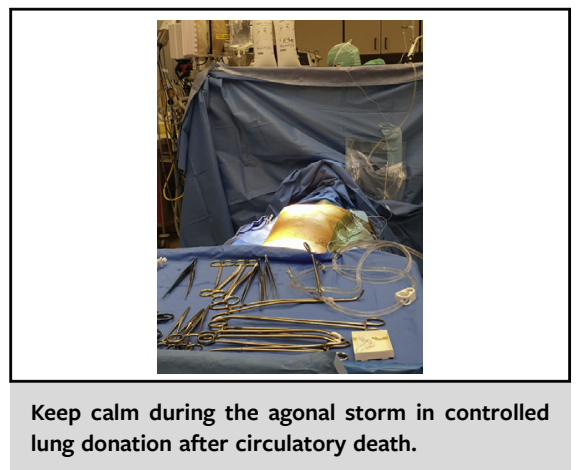

CENTRAL MESSAGE

Transplant lungs from

circulatory-dead donors can be

safely recovered at long intervals

after withdrawal from life-

sustaining therapy if functional

warm ischemic time before cold

flush remains short.

used in their hands. They assessed whether the duration of documented agonal phase in $180 \mathrm{cDCDDs}$ (rapid: 0-19 minutes [ $\mathrm{n}=90]$, intermediate: $20-59$ minutes $[\mathrm{n}=38]$, or long: $>60$ minutes $[\mathrm{n}=20]$ ) influenced post-LTx outcome compared with 1088 donors after neurologic determination of death (DNDD). No significant differences were found in short- and long-term recipient survival, primary graft dysfunction, intensive care unit stay, mechanical ventilation days, or total hospital stay.

Two intriguing findings are important to consider for other teams to feel comfortable with increasing their agonal phase cutoffs. First, the hypotensive period starting with systolic blood pressure $<50$ to $60 \mathrm{~mm} \mathrm{Hg}$ (T2) until asystole (T3) was intriguingly short in the Toronto experience and did not differ between the 3 cDCDD groups (rapid: $3.7 \pm 3.8$ minutes, intermediate: $7.5 \pm 7.7$ minutes, and long: $8.1 \pm 11.8$ minutes; $P=.06$ ). The period T2 to T3 is generally considered the most important trigger inducing lung injury as blood flow cessation induces an endothelial response by change in shear stress rather than by hypoxia. ${ }^{6}$ This might explain the excellent outcomes of cDCDD lungs exposed to a prolonged agonal phase. Furthermore, the time between asystole and cold flush (T3-T5), as well as functional WIT (T2-T5) might be important determinants of outcome and have not been investigated. Indeed, for kidneys the asystolic time determines primary nonfunction ${ }^{7}$ 
TABLE 1. Specific time points in the setting of a controlled donation after circulatory death donor from withdrawal from life-sustaining therapy until lung preservation by cold flush

\begin{tabular}{|c|c|c|c|c|c|}
\hline \multicolumn{3}{|c|}{ Controlled donation after circulatory death } & \multirow{2}{*}{$\frac{\text { ISHLT }^{*}}{\text { Time point }}$} & \multicolumn{2}{|c|}{ ESOT $\dagger$} \\
\hline Event & Agonal phase & Asystolic phase & & $\begin{array}{l}\text { Total } \\
\text { WIT }\end{array}$ & $\begin{array}{c}\text { Functional } \\
\text { WIT }\end{array}$ \\
\hline Withdrawal of life-sustaining therapies & - & & T0 & - & \\
\hline Oxygen saturation $<80 \%$ & - & & $\mathrm{T} 1$ & - & \\
\hline Systolic blood pressure $<50 \mathrm{~mm} \mathrm{Hg}$ & - & & $\mathrm{T} 2$ & - & - \\
\hline Cessation of cardiac output/asystole & & - & $\mathrm{T} 3$ & - & - \\
\hline Resumed lung inflation/ventilation & & - & $\mathrm{T} 4$ & - & - \\
\hline Start of pulmonary flush & & - & T5 & - & - \\
\hline
\end{tabular}

ISHLT, International Society for Heart and Lung Transplantation; ESOT, European Society for Organ Transplantation; WIT, warm ischemic time. *Defined by the DCD Registry Steering Committee of the ISHLT. Cypel M, Levvey B, Van Raemdonck D, Erasmus M, Dark J, Love R, et al. International Society for Heart and Lung Transplantation Donation After Circulatory Death Registry Report. J Heart Lung Transplant. 2015;34:1278-82. †Defined by the European Working Group of the ESOT. ${ }^{3} \ddagger$ Including the no-touch period.

and for liver evidence suggests functional WIT to be a more important risk factor for posttransplant cholangiopathy. ${ }^{8}$ Certain events can lengthen these times; for example, transporting the donor when WLST does not take place in the operating room (Figure 1). In addition, cDCDD lung retrieval is often part of a multiorgan retrieval. Because abdominal organs are more vulnerable to WIT, priority may be given to rapid recovery of liver and kidneys while lungs remain in the chest after cold flush and topical cooling. This will increase pneumonectomy time that might influence outcomes, similar to those in kidney ${ }^{9}$ and liver. ${ }^{10}$

Second, it is important to realize that Qaqish and colleagues ${ }^{5}$ frequently and selectively uses pretransplant evaluation by ex vivo lung perfusion (EVLP). Although good outcomes without EVLP have been reported in CDCDD $\mathrm{LTx},{ }^{2}$ in the current study, pre-LTx EVLP was used in

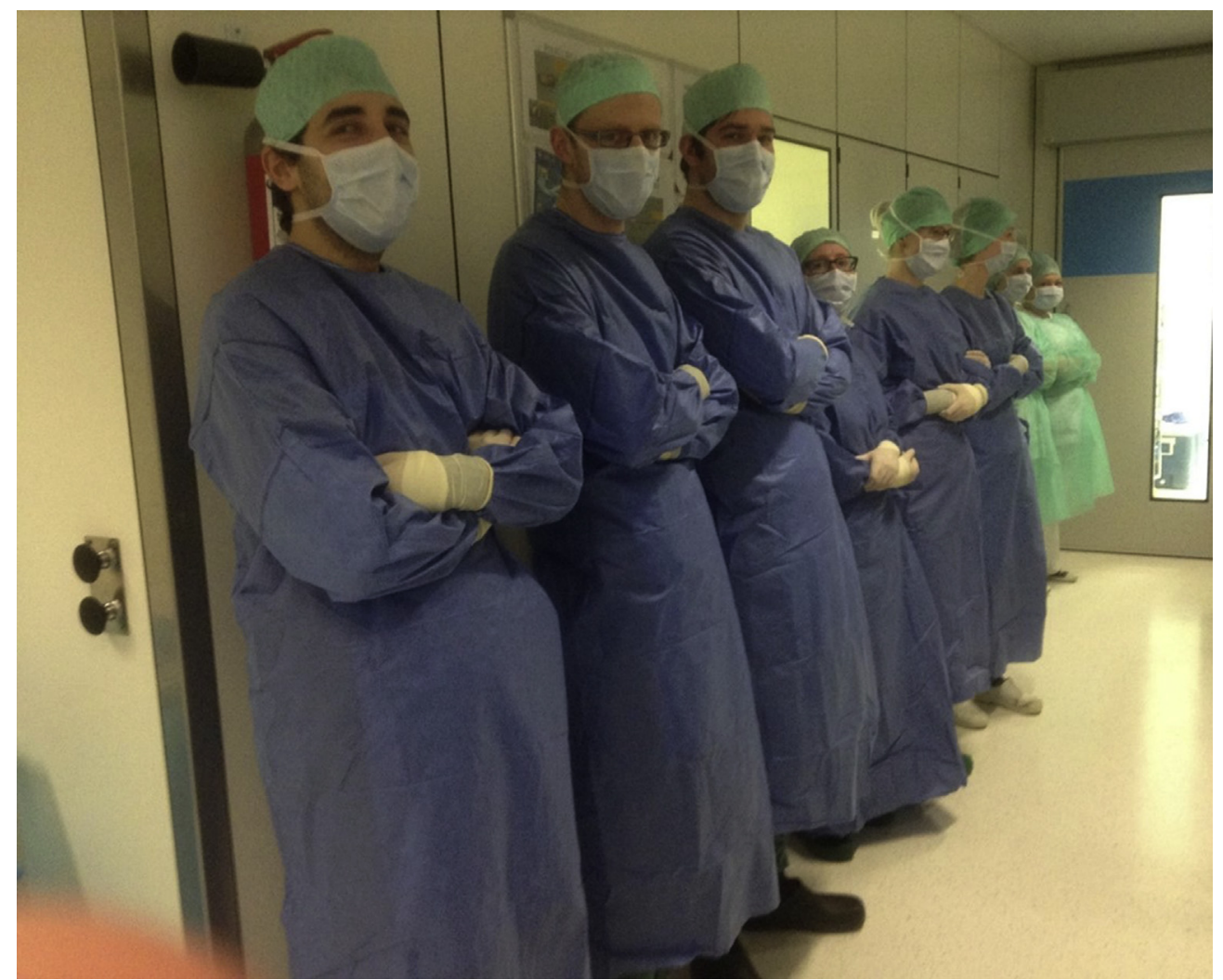

FIGURE 1. Multiorgan recovery team at the University Hospitals Leuven, Leuven, Belgium. While the lead anesthesiologist ensures that the consented donor receives comfort therapy during the agonal phase, the scrubbed team is waiting outside the operating room for circulatory arrest following withdrawal from life-sustaining therapy. A 5-minute no-touch period is respected. Surgery is not started until death has been certified by 3 independent physicians. 
$65.6 \%$ of cDCDDs and $13.7 \%$ of DNDD. All 20 lungs in donors with an agonal phase $>60$ minutes underwent EVLP despite short $\mathrm{T} 2$ to $\mathrm{T} 3$ times comparable to donors with short and intermediate agonal phases. Although recipient survival rates were similar between EVLP and nonEVLP LTx, the exact role of EVLP remains unclear.

During the same time period as the Toronto study, ${ }^{5} 664$ isolated LTx were performed at the University Hospitals Leuven, Belgium, including $125(18.8 \%)$ with cDCDD lungs. The mean agonal and asystolic phase (including $5 \mathrm{mi}-$ nutes no touch) were 11.6 minutes (range, 0-49 minutes) and 9.9 minutes (range, 2-24 minutes), respectively. As such, total WIT was only 21.6 minutes (range, 2-71 minutes). Except for 5 cases enrolled in the Expand study, all cDCDD lungs were transplanted without prior EVLP. Short and long-term post-LTx recipient outcome was similar between cDCDDs versus DNDDs. ${ }^{11}$

An important reason for success for any cDCDD program is the selection of potential donors based on objective criteria. It would have been interesting if the authors provided more details on patient's medical status, their selection process, any premortem intervention focusing on donor comfort, and the number of aborted procedures to gain more insight in how to optimize cDCDD organ donation worldwide.

Organ retrieval practice in cDCDDs is likely to change considerably as an increasing number of centers are introducing abdominal normothermic regional perfusion to preserve abdominal organs in situ. The optimal preservation strategy is still not clear and the role of thoracoabdominal normothermic regional perfusion is currently unknown. ${ }^{12-14}$

Qaqish and colleagues ${ }^{5}$ add to the evidence not to panic if the agonal phase in cDCDDs is prolonged. Further research is needed to clarify which parameters during the different phases of total WIT ultimately influence organ quality. Meanwhile, keep calm amid the agonal storm!

\section{References}

1. Neyrinck A, Van Raemdonck D, Monbaliu D. Donation after circulatory death: currents status. Curr Opin Anesthesiol. 2013;26:382-90.

2. Van Raemdonck D, Keshavjee S, Levvey B, Cheikh WS, Snell G, Erasmus M, et al. Donation after circulatory death in lung transplantation-five-year follow-up from ISHLT Registry. J Heart Lung Transplant. 2019;38:1235-45.

3. Thuong M, Ruiz A, Evrard P, Kuiper M, Boffa C, Akhtar MZ, et al. New classification of donation after circulatory death donors definitions and terminology. Transpl Int. 2016;29:749-59.

4. Levvey B, Keshavjee S, Cypel M, Robinson A, Erasmus M, Glanville A, et al. Influence of lung donor agonal and warm ischemic times on early mortality: analyses from the ISHLT DCD Lung Transplant Registry. J Heart Lung Transplant. 2019;38:26-34.

5. Qaqish R, Watanabe Y, Hoetzenecker K, Yeung J, Chen M, Pierre A, et al. Impact of donor time to cardiac arrest in lung donation after circulatory death. J Thorac Cardiovasc Surg. 2021;161:1546-55.e1.

6. Song C, Al-Mehdi AB, Fisher AB. An immediate endothelial cell signaling response to lung ischemia. Am J Physiol Lung Cell Mol Physiol. 2001;281: L993-1000.

7. Heylen L, Jochmans I, Samuel U, Tieken I, Naesens M, Pirenne J, et al. The duration of asystolic ischemia determines the risk of graft failure after circulatory-dead donor kidney transplantation: a Eurotransplant cohort study. Am J Transplant. 2018;18:881-9.

8. Coffey JC, Wanis KN, Monbaliu D, Gilbo N, Selzner M, Vachharajani N, et al. The influence of functional warm ischemia time on DCD liver transplant recipients' outcomes. Clin Transplant. 2017;31.

9. Heylen L, Pirenne J, Samuel U, Tieken I, Coemans M, Naesens M, et al. Effect of donor nephrectomy time during circulatory-dead donor kidney retrieval on transplant graft failure. Br J Surg. 2020;107:87-95.

10. Jochmans I, Fieuws S, Tieken I, Samuel U, Pirenne J. The impact of hepatectomy time of the liver graft on post-transplant outcome: a Eurotransplant cohort study. Ann Surg. 2019;269:712-7.

11. Ruttens D, Martens A, Ordies S, Verleden SE, Neyrinck AP, Vos R, et al. Short- and long-term outcomes after lung transplantation from circulatory-dead donors: a single-center experience. Transplantation. 2017;101:2691-4.

12. Miñambres E, Ruiz P, Ballesteros MA, Álvarez C, Cifrián JM, Atutxa L, et al. Combined lung and liver procurement in controlled donation after circulatory death using normothermic abdominal perfusion. Initial experience in two Spanish centers. Am J Transplant. 2020;20:231-40.

13. O'Neill S, Srinivasa S, Callaghan CJ, Watson CJ, Dark JH, Fisher AJ, et al. Novel organ perfusion and preservation strategies in transplantation-where are we going in the UK? Transplantation. January 13, 2020 [Epub ahead of print].

14. Tsui SSL, Oniscu GC. Extending normothermic regional perfusion to the thorax in donors after circulatory death. Curr Opin Organ Transplant. 2017;22: $245-50$. 